\title{
Współczesna recepcja antyku grecko-rzymskiego w Polsce
}

DOI: http://dx.doi.org/10.12775/LC.2018.044

Streszczenie: Obecność kultury antycznej w życiu współczesnego człowieka od lat ulega drastycznej redukcji. Niemniej wydaje się, że badania nad starożytnością klasyczną oraz przede wszystkim jej wpływami na kulturę nowożytną rozwijają się dobrze. Celem artykułu, ze względu na charakter tego tomu, jest próba syntetycznego ujęcia współczesnych badań właśnie nad recepcją antyku grecko-rzymskiego w kulturze polskiej ze wskazaniem wybranej literatury przedmiotu oraz dominujących tendencji, wśród których obok wciąż rozwijających się badań literackich do głosu coraz częściej dochodzą te skoncentrowane na recepcji mitów, recepcji antyku w teatrze czy w kulturze popularnej. Przykładowym ujęciem, na podstawie którego chcemy wskazać funkcjonowanie motywu antycznego na różnych poziomach, jest historia obecności Antygony w polskim teatrze.

Słowa kluczowe: recepcja, antyk, literatura, kultura, Antygona

\section{Contemporary Reception of Greek and Roman Antiquity in Poland}

\footnotetext{
Abstract: The presence of the culture of Antiquity among contemporary people has been dramatically reduced over the past few decades. Nevertheless, research on Classical Antiquity, and particularly its influence on modernity, continues to develop vigorously. The article aims to synthetically present contemporary research on the reception of Greek and Roman Antiquity in Polish culture, as

* Dr hab., adiunkt w Katedrze Filologii Klasycznej UMK. Zainteresowania badawcze: dramat antyczny i jego recepcja; problematyka przekładów z języków klasycznych; dziedzictwo grecko-rzymskiego antyku. E-mail: bb@umk.pl.

** Dr, adiunkt na Wydziale „Artes Liberales” UW i w Kolegium MISH UW, wykładowca Akademii Teatralnej im. A. Zelwerowicza, teatrolog, krytyk teatralny i eseista. Zainteresowania badawcze: historia teatru i dramatu, kultura modernizmu i Młodej Polski, recepcja antyku. E-mail: mizera@al.uw.edu.pl.
} 
well as to provide a selection of literature on the subject and outline the dominant tendencies. The history of the presence of Antigone in Polish culture provides an example which serves to demonstrate how an Antique motif functions in various dimensions.

Keywords: reception, Antiquity, literature, culture, Antigone

becność starożytności w życiu współczesnego młodego człowieka ma charakter szczątkowy, incydentalny, co stanowi konsekwencję radykalnej przebudowy programów nauczania w polskim systemie edukacyjnym po II wojnie światowej, z którego kształcenie klasyczne zostało niemal wyrugowane ${ }^{1}$. Coraz mniej jest zatem naturalnych użytkowników kultury antycznej kształconych przed wojną, zaś kolejne pokolenia nie zakorzeniają wspólnego języka i wyobraźni ani w przygodach Odyseusza, ani w podbojach Cezara czy Aleksandra Wielkiego. W konsekwencji nie ma komu ani dla kogo budować komunikatów opartych o pojęcia, symbole i obrazy zanurzone w tradycji antycznej. Odniesienia do starożytności już dawno przestały być istotnym elementem komunikacji publicznej i wspólnotowej, stając się przedmiotem zainteresowania pasjonatów, specjalistów i erudytów, słowem stając się przedmiotem niszowym i skazanym na elitaryzm. Wielbiciele kultury antycznej nie tracą wszak nadziei, że zgodnie z sinusoidalną dynamiką procesów kulturowych antyk wróci do łask i ponownie stanie się elementem powszechnego systemu komunikacji. Warto zastrzec na wstępie, że w tym opracowaniu, ze względu na charakter całego tomu, zajmiemy się przede wszystkim polskimi badaniami recepcyjnymi grecko-rzymskiego antyku, w rozumieniu „sposobów, w jaki grecko-rzymski materiał jest transmitowany, tłumaczony, wybierany, interpretowany, przepisywany, ponownie wyobrażany, przedstawiany" (Hardwick, Stray 2008: 1)² przez późniejszych (poantycznych) twórców, pozostawiając na marginesie te odnoszące się do samego antyku, antycznego chrześcijaństwa czy pozostałych kultur śródziemnomorskich. Zabieg ten, konieczny ze względu na ramy artykułu, pozwoli dodatkowo wyostrzyć punktowy i okazjonalny, związany z zainteresowaniami konkretnych badaczy, charakter podejmowanych inicjatyw.

Ze względu na zmianę w sposobie prowadzenia badań naukowych wiele wskazuje też na to, że minął czas autorskich syntez naukowych na rzecz zespołowych opracowań, pisanych przez specjalistów od poszczególnych zagadnień, tomów wydawanych często pod redakcją kolegium, a nie jednej osoby, czego najwyraźniejszym przykładem jest monumentalna Literatura Grecji starożytnej wydana w dwóch tomach pod redakcją Henryka Podbielskiego (Lublin 2005) w zestawieniu chociażby z Literatura grecka wydawaną $\mathrm{w}$ trzech tomach

1 Wśród polskich publikacji na ten temat znajdziemy liczne poświęcone nauczaniu antyku na wybranych uniwersytetach (np. Brzuska 1992), jak też skoncentrowane na języku łacińskim i jego dziedzictwie europejskim (np. Hermann 2014).

2 Zdajemy sobie sprawę, podobnie jak autorzy cytowanego tomu, ze złożoności tego procesu i faktu, że każde nowe przeobrażenie antycznego materiału jest częścią znacznie bardziej skomplikowanych procesów i kontekstów kulturowych. Mamy również świadomość, że w polskiej literaturze przedmiotu niejednokrotnie brakuje precyzji co do rozumienia tego pojęcia, jak również dyskusji co do kwestii ewentualnego rozdzielenia badań recepcyjnych od badań nad tradycją antyczną (jaka toczy się w anglosaskiej literaturze przedmiotu, por. Budelman, Haubold 2008: 13-25). Pogłębienie tej kwestii zasługiwałoby jednak na osobny artykuł. 
w latach 1931-1954, a napisaną wyłącznie przez Tadeusza Sinkę. Wciąż nie powstają u nas także wydawnictwa o charakterze propedeutycznym czy wręcz podręcznikowym o charakterze tak popularnych na Zachodzie „companionów”, dostępnych w Polsce w dobrych bibliotekach (głównie uniwersyteckich).

Przegląd polskiej literatury przedmiotu poświęconej recepcji antyku pozwala stwierdzić, że dominują w niej pozycje poświęcone wybranym - przede wszystkim literackim aspektom zagadnienia. Swoistą serię badań recepcyjnych rozpoczęły publikacje Tadeusza Sinki: Hellenizm Juliusza Stowackiego (1909), Jedno ze źródeł „Irydiona” (1912), Rzym pogański w „Irydionie” (1912), Eacińskie prace Krasińskiego (1912), Antyk Wyspiańskiego (1916), Genealogia kilku typów i figur A. Fredry (1918), Echa klasyczne w literaturze polskiej. Dwanaście studiów i szkiców (1923), O tradycjach klasycznych Adama Mickiewicza: rozpraw pięcioro (1923), Powinowactwo klasyczności i romantyczności (1924), Klasyczny laur Norwida (1933), Hellada i Roma w Polsce: przeglad utworów na tematy klasyczne w literaturze polskiej ostatniego stulecia (1933), Od filantropii do humanizmu i humanitaryzmu (1939), Posag Europy i jego losy (1947), Mickiewicz i antyk (1957)³. Prace Sinki wyznaczają z pewnością dwie ścieżki dalszych badań recepcyjnych, tych poświęconych poszczególnym aspektom recepcji oraz syntetycznym ujęciom wpływów literatury antycznej na polską. Za kontynuację książki Hellada i Roma w Polsce Sinki można uznać publikacje Stanisława Stabryły: Antyk we wspótczesnej literaturze polskiej (1980), Hellada i Roma w Polsce Ludowej. Recepcja antyku w literaturze polskiej w latach 1945-1975 (1983), Hellada i Roma: recepcja antyku w literaturze polskiej w latach 1976-1990 (1996) oraz syntetyczne w swym ujęciu rozważania o recepcji antyku w kulturze polskiej zawarte w Zarysie kultury starożytnej Grecji $i$ Rzymu (2016). Wśród publikacji natomiast, które prezentują wybrane zagadnienia związane z tematem, można wymienić np.: Gabrieli Pianko Antyk we wspótczesnym teatrze polskim: $w$ dwudziestolecie powstania Polskiej Rzeczypospolitej Ludowej (1965), Zygmunta Kubiaka Wędrówki po stuleciach (1969), Wojciecha Stańczaka Antyk we wspótczesnej poezji polskiej: 1956-1980 (1986), Jerzego Starnawskiego, Marii Wichowej, Andrzeja Obrębskiego Antyk w Polsce, cz. 1 (1992), Topikę antyczną w literaturze polskiej XX wieku (1992) pod redakcją Elżbiety Sarnowskiej-Temeriusz i Aliny Brodzkiej, Mit, człowiek, literatura (1992) ze wstępem Stabryły, Aleksandra W. Mikołajczaka Antyk w poezji Macieja Kazimierza Sarbiewskiego (1994), Jerzego Starnawskiego i Jana Okonia Antyk w Polsce, cz. 2: Studia (1998), Literaturę i czasopiśmiennictwo polskie 1864-1918 wobec tradycji antycznej pod redakcją Andrzeja Z. Makowieckiego (2000), Juliusza Domańskiego Philologica, Litteraria, Humaniora. Studia i szkice $z$ dziejów recepcji dziedzictwa antycznego (2009). Na uwagę zasługują także autorskie eseje nawiązujące do tradycji grecko-rzymskiego antyku, szczególnie w odniesieniu do jego znaczenia dla współczesnego człowieka, o charakterze confessio, jak Jana Parandowskiego Dysk olimpijski (1933), Zygmunta Kubiaka Brewiarz Europejczyka (1998), Uśmiech Kore (2000), Nowy brewiarz Europejczyka (2001a), Pótmrok ludzkiego świata (2001b), Zbigniewa Herberta Labirynt nad morzem (2000, pośmiertnie), Jacka Bocheńskiego Antyk po antyku (2010) czy Jerzego Starnawskiego Antyk wciąż żywy (2010). Skoncentrowanie się na wybranych, bliskich zainteresowaniom danego autora kwestiach z konieczności wymusza subiektywne spojrzenie tak na istotną rolę antyku w kulturze, jak i na jego obecność w kulturze polskiej, co w konsekwencji prowadzi do narzekań niektórych autorów na stopnio-

3 Część tych pozycji została przedrukowana w Sinko 1988. 
wą dewaluację spuścizny antyku i miałkość odwołań do kultury klasycznej (znamienne, że opracowania te zwykle nie obejmują najnowszych wpływów kultury antycznej na kulturę współczesną). Do opracowań obejmujących wpływ antyku w danej epoce literackiej należą prace pod redakcją Tadeusza Bieńkowskiego Antyk w literaturze i kulturze staropolskiej: (1450-1750): główne problemy i kierunki recepcji (1976) czy Stanisława Lorentza Antyk w kulturze Oświecenia (1989). Na uwagę zasługuje także seria obejmująca na chwilę obecną aż dwanaście tomów (wychodzących od 2001 roku) „Antyk romantyków”4, poświęconych różnym aspektom obecności antyku w tej epoce (w skład rady naukowej serii wchodzą: Jerzy Axer, Jerzy Speina oraz Włodzimierz Szturc). Cykl ten zapoczątkowały projekty Marii Kalinowskiej (będącej również redaktorem naczelnym serii). Realizowane są one w Ośrodku Badań nad Tradycją Antyczną Uniwersytetu Warszawskiego (dzisiaj znajdującym się w strukturze Wydziału „Artes Liberales”), cenionym ze względu na prowadzone w nim badania nad recepcją antyku, które w Polsce, na znaczniejszą skalę, zostały zapoczątkowane właśnie przez ten ośrodek.

$\mathrm{Z}$ pewnością nie są to wszystkie dostępne publikacje, a w rozproszonych w czasopismach czy księgach zbiorowych artykułach znajdują się kolejne - poświęcone różnym zagadnieniom literackim oraz poszczególnym przedstawicielom literatury polskiej od Jana Kochanowskiego do Zbigniewa Herberta. Warto dodać, że w ramach badań recepcyjnych powstają także liczne prace poświęcone wybranym aspektom dotyczącym nawiązań do antyku w sztukach plastycznych, przygotowywane na podstawie polskich zbiorów muzealnych, jak Elżbiety Jastrzębowskiej Antykw Zamku Królewskimw Warszawie (1993), Dariusza Chojeckiego Antyk w zbiorach muzeów Górnego Śląska (2000), Witolda Dobrowolskiego Wazy greckie Stanisława Kostki Potockiego (2007) czy Krystyny Gutowskiej-Dudek Między światem mitów i legend a wspótczesnością. Louis de Silvestre - nadworny malarz królów Polski $z$ dynastii Wettynów (2015).

Nowymi i zyskującymi na znaczeniu kierunkami zainteresowań w polskich badaniach recepcji antyku, dotychczas skoncentrowanych przede wszystkim na literaturze, są publikacje poświęcone kulturze popularnej: Antyk w zwierciadle literatury i kultury popularnej pod redakcją Aleksandra Mikołajczaka, Konrada Dominasa i Rafała Dymczyka (2015) czy też Konrada Dominasa Internet jako nowa przestrzeń recepcji literatury antycznej (2017). Recepcji antyku w kulturze popularnej część swoich badań naukowych poświęca również Aleksandra Klęczar z Uniwersytetu Jagiellońskiego, zajmująca się obecnością tradycji antycznej w twórczości Johna R. R. Tolkiena, Joanne K. Rowling, Neila Gaimana, Arthura Conana Doyle’a. Zważywszy na to, że liczni polscy twórcy teatralni, jak Maja Kleczewska, Krzysztof Warlikowski, Jan Klata, Michał Zadara i inni, wykorzystują antyk w swoich przedstawieniach, należy spodziewać się kolejnych publikacji analizujących to zagadnienie, pisanych nie tylko przez filologów klasycznych, ale także teatrologów, polonistów czy kulturoznawców. Zupełnie świeżą publikacją w tym zakresie jest monografia Małgorzaty Budzowskiej z Uniwersytetu Łódzkiego zatytułowana Sceniczne metamorfozy mitu. Teatr polski XXI wieku w perspektywie kulturowej (2018).

\footnotetext{
${ }^{4}$ Najnowszą publikacją w ramach serii jest dwutomowa praca powstała w ramach projektu: „Sparta w literaturze i kulturze polskiej - od okresu staropolskiego do XX wieku. Między recepcją dziedzictwa greckiego a poszukiwaniem narodowej tożsamości": Borowska, Kalinowska, Speina, Tomaszuk 2014 oraz Borowska, Kalinowska, Kaja, Speina 2015.
} 
Wśród nowszych publikacji można zauważyć - zaskakujące, jeśli weźmiemy pod uwagę ich szczątkową obecność w szkole - zainteresowanie mitami starożytnymi i ich recepcją w kulturze. Opowieści mitologiczne wciąż bowiem stymulują wyobraźnię tak światowych, jak i polskich twórców. Stanowią one kod kulturowy, który jest przywoływany w coraz nowszych kontekstach, wciąż aktualizowany, tworzący nowe przekazy i oddający emocje nowych pokoleń użytkowników (por. Katarzyna Marciniak, Mitologia grecka i rzymska, WarszawaBielsko-Biała 2010), jakby zgodnie z ustaleniami uczonych spod znaku kulturowych badań nad przekładem (por. Heydel 2009: 21-33), którzy twierdzą, że nowe konteksty warunkują nowe odczytania dzieł, zależne od danej kultury, danych okoliczności czy danego odbiorcy. Dlatego też stają się one przedmiotem badań i kolejnych interpretacji spod znaku antropologii, psychologii, psychoanalizy, strukturalizmu, postkolonializmu, postdramatyczności, postmodernizmu czy krytyki feministycznej. Jak pisze Marciniak (2013: 206-207), „w badaniach nad recepcją rola odbiorcy ma znaczenie szczególne [...]. Antyk służy jako zwierciadło, w którym przeglądają się wszyscy członkowie wspólnoty opartej na tradycji śródziemnomorskiej”. Wśród publikacji należących do tego nurtu badań można wymienić dwie pozycje, będące pokłosiem organizowanych na Uniwersytecie Łódzkim konferencji: Ancient Myths in the Making of Culture pod redakcją Małgorzaty Budzowskiej i Jadwigi Czerwińskiej (2014) oraz The Metamorphoses of Ancient Myths pod redakcją Małgorzaty Budzowskiej, Burca I. Dinçela, Jadwigi Czerwińskiej i Katarzyny Chiżyńskiej (2017). Poza publikacjami naukowymi pojawiają się także wydawnictwa o charakterze popularyzatorskim, te skierowane do najmłodszej części odbiorców, jak dwa tomy Mitów dla dzieci Grzegorza Kasdepkego (2009, 2011) czy dwa tomy Mojej pierwszej mitologii Marciniak (2016a; 2016b), jak również do nieco starszej publiczności, w tym opowieść mitologiczna Stabryły Klątwa Pelopidów (1995) . Szczególnie cenne w związku z tym aspektem badań recepcyjnych są ustalenia zespołu badawczego Katarzyny Marciniak z Wydziału „Artes Liberales” Uniwersytetu Warszawskiego w ramach projektu „Our Mythical Childhood”, który zajmuje się recepcją antyku w kulturze dziecięcej i młodzieżowej. W ramach projektu powstał katalog literatury dziecięcej i młodzieżowej: Polish Literature for Children \& Young Adults inspired by Classical Antiquity (2013, dostępny on-line), jak również publikacja Our Mythical Childhood... The Classics and Literature for Children and Young Adults, zredagowana przez Marciniak (2016) w ramach serii „Metaforms. Studies in the Reception of Classical Antiquity" wydawnictwa Brill ${ }^{6}$. Działaniom tym patronuje przekonanie zakorzenione w środowisku filologów klasycznych przez Tadeusza Zielińskiego, rzecznika kształcenia klasycznego, którego dzieła poświęcone światu antycznemu do dzisiaj są czytane: „Antyk powinien być dla nas nie normą, lecz nasieniem. Nie normą, to znaczy nie wzorem dla naśladowania; nasieniem, to znaczy środkiem zapładniającym nasze umysły,

${ }_{5}^{5}$ Na marginesie można zauważyć, że antyk bywa także inspiracją dla polskich twórców literatury kryminalnej, jak np. Marka Krajewskiego, by wymienić tylko powieści nawiązujące tytułami do kultury antycznej: Głowa Minotaura (2009), Erynie (2010), Liczby Charona (2011), Rzeki Hadesu (2012), Jakuba Szamałka Kiedy Atena odwraca wzrok (2011) czy Marty Guzowskiej Ofiara Polikseny (2012) i Głowa Niobe (2013).

6 Można dodać, że w serii tej, wydawanej od 2012 roku, opublikowano dwanaście tomów poświęconych szeroko rozumianej recepcji kultury starożytnej, szczególnie literaturze, filmowi, sztukom wizualnym, ale nie tylko, dotykających problemu z różnych perspektyw badawczych, http://www.brill.com/publications/metaforms [31.07.2017]. Inną serią wydawniczą poświęconą recepcji jest „New Voices in Classical Reception Studies”, wydawana od 2006 roku: http://fass.open.ac.uk/research/newvoices [31.07.2017]. 
jako ludzi nowoczesnych, celem wydania owoców, odpowiadających wymaganiom naszych czasów” (Zieliński 1970: 399).

Prowadzone na polskich uniwersytetach badania poświęcone naukom o starożytności pozwalają spodziewać się kolejnych pozycji typu case studies. Z realizowanych w chwili obecnej około sześćdziesięciu grantów finansowanych ze środków NCN i NPRH jednak tylko dwa, z tego, co udało się nam ustalić, są poświęcone zagadnieniom recepcji grecko-rzymskiego antyku: projekt Budzowskiej dotyczący recepcji mitów antycznych z kręgu kultury śródziemnomorskiej w teatrze polskim XXI wieku (który zaowocował przywołaną wyżej książką) oraz Marka Piechowiaka poświęcony koncepcji sprawiedliwości Platona w perspektywie współczesnego ugruntowania prawa w godności człowieka. Nadzieją na wzmocnienie tego kierunku badań był kolejny konkurs w ramach NPRH Dziedzictwo narodowe, którego obszarem priorytetowym było dziedzictwo starożytności w kulturze polskiej. Niestety, wśród projektów zakwalifikowanych do finansowania nie znalazł się żaden poświęcony naukom o starożytności.

Prężnie, mimo pewnych problemów, rozwija się także seria „Biblioteka Antyczna” od roku 1998 prezentująca przekłady literatury starożytnej, początkowo ukazująca się w wydawnictwie Prószyński i S-ka (1998-2008), od 2012 w Wydawnictwie Uniwersytetu Wrocławskiego. Jak dotąd w serii ukazało się blisko siedemdziesiąt tomów dzieł, kolejnych kilkanaście zostało już zaplanowanych. Na marginesie można jedynie ze smutkiem skonstatować, że mimo powstających - niekiedy po raz pierwszy, niekiedy na nowo zredagowanych czy kolejnych - tłumaczeń w stosunkowo niewielkim stopniu uwagę badaczy przyciąga refleksja translatologiczna, zwłaszcza wobec intensywnie rozwijających się badań przekładoznawczych. Do chlubnych wyjątków można zaliczyć artykuły, które ukazały się w publikacji pod redakcją Michała Rusinka O sztuce tłumaczenia (1955) czy w publikacji Przektad artystyczny. O sztuce tłumaczenia, księga druga pod redakcją Seweryna Pollaka (1975). Wymienić można także poszczególne głosy: Stefana Srebrnego (1984: 184-201), Artura Sandauera (1977:352-357), Jana Wikarjaka (1977: 91-173), Mieczysława Brożka (1996: 397-399), Jerzego Łanowskiego (1997: 179-185), Zbigniewa Nerczuka (2016: 13-19), książkę Radosława Rusnaka poświęconą przekładom tragedii Seneki (2009) oraz Marii Wichowej analizującej staropolskie przekłady Metamorfoz Owidiusza (2008). W najobszerniejszym wymiarze problematyka ta pojawiła się w pracach Ewy Skwary z Uniwersytetu im. Adama Mickiewicza (1996; 2004; 2008; 2009; 2012), badaczki i tłumaczki komedii Plauta i Terencjusza, oraz w badaniach współautorki tego artykułu (Bibik 2006; 2012; 2009-2012; 2015; 2016a; 2016b; 2016c; 2016d; 2016e). Przekładom z języków starożytnych zostały poświęcone jedynie pojedyncze tomy czasopism: „Symbolae Philologorum Posnaniensium” (2004), „Literatury na Świecie” (1996) i „Przekładańca” (2007); niewielką garść informacji na ten temat można również odnaleźć we wstępach do ukazujących się przekładów z literatury starożytnej, a wychodzących we wspomnianej serii „Biblioteka Antyczna” czy też w wydawnictwie Homini (Katullus 2013; Tibullus 2015).

Tym skrótowym katalogiem najważniejszych, naszym zdaniem, trendów w polskim piśmiennictwie związanym $\mathrm{z}$ recepcją tradycji antycznej chcielibyśmy zakończyć pierwszą część naszego artykułu. W drugiej natomiast pragniemy na jednym, wybranym przez nas przykładzie w praktyce ukazać wielość i różnorodność możliwych ujęć recepcji antyku w polskiej kulturze, jego funkcjonowanie w życiu publicznym i kulturalnym. Chcemy na- 
świetlić ten problem na przykładzie bodaj najbardziej oczywistym, czyli obecności mitu Antygony na scenie polskiej po II wojnie światowej.

$\mathrm{Z}$ wielu powodów właśnie mit Antygony zdaje się emblematyczny dla specyficznie polskiej recepcji kultury antycznej. Wykazywał on bowiem jakąś szczególną podatność na „polonizację" i po prostu często był w naszej kulturze przywoływany. W tym momencie interesuje nas zatem wpisywanie tzw. wielkich ksiąg, fundamentalnych dla kultury europejskiej mitów w narodowe strategie komunikacyjne ważne dla określonej zbiorowości. Oczywiście szczególne natężenie takich zabiegów będzie następowało zawsze wtedy, kiedy utrudnione jest prowadzenie komunikacji na normalnych zasadach, czyli np. w czasach tak czy inaczej rozumianego zniewolenia. Że nie jest to specyfika tylko polska i że możliwe okazuje się wpisywanie współczesnych strategii także na poziomie ponadnarodowym, świadczy praca George’a Steinera Antigones (1996), w której autor bardzo skrupulatnie wylicza różne przetworzenia antycznego mitu znanego najpowszechniej z tragedii Sofoklesa. Jego książka to niemal sztandarowy przykład odpowiedzi na to, w jakim zakresie mity antyczne towarzyszyły człowiekowi w wędrówce przez wieki i w jakim stopniu mogą one stanowić o żywym, autentycznym porozumieniu między współczesnymi ludźmi, na ile jeszcze mogą pełnić rolę zrozumiałego nośnika intencji w procesie komunikacji znacznie oddalonym w czasie od źródeł, w jakich powstały.

Obecność tekstów antycznych w teatrze polskim jest ściśle powiązana z rozwojem filologii klasycznej, która w XIX wieku stała się prawdziwą królową humanistyki. Na gruncie polskim to właśnie przełom XIX i XX stulecia stał się apogeum obecności antyku w literaturze, w dramacie i na scenie, głównie za sprawą Stanisława Wyspiańskiego. Także początki polskiej teatralnej recepcji utworu Sofoklesa sięgają samego przełomu XIX i XX wieku, kiedy to w roku 1898 Kazimierz Morawski wydaje swój przekład Antygony, który za kilka lat posłuży Wyspiańskiemu do wystawienia tego dramatu na scenie. Słynna fraza „współkochać przyszłam, nie współnienawidzić” już na stałe wchodzi do słownika skrzydlatych słów i do kanonu tłumaczeń na tyle silnie, że przezwycięża nawet opory rasowych filologów klasycznych, świadomych niedokładności tłumaczenia tej frazy. W tym momencie bardziej interesujące jednak niż samo tłumaczenie staje się to, że autor przekładu umieścił swój wiersz jako rodzaj prologu do własnego tłumaczenia. Nosi on podtytuł Przygrywka do polskiej Antygony i rozpoczyna się tak:

Dzieweczko grecka, biała Antygono,

Zstąp dziś pomiędzy nas synów północy,

Odsłoń nam burze, co szarpią twe łono.

Stań w twojej sile i twojej niemocy.

By nam wyśpiewać hymn chwały i klęski.

I tchnąć w słuchaczów czar słowa zwycięski.

(za: Zabierowski 1978: 163-165)

Polska Antygona powinna wypełniać wzór virago, „mężyny”, który w polskiej tradycji rozpoczyna się od legendarnej Wandy. Bardzo wyraźnie Morawski zapowiada w swojej Przygrywce nie tylko polonizację Antygony, ale i - nieodłącznie - jej chrystianizację. Antygona stoi na czele całego pochodu dzielnych dziewcząt, który poprzez wieki prowadzi aż do współczesności. Te dziewczęta są przecież w sposób jednoznaczny i niebudzący wątpliwości przedstawione jako chrześcijańskie męczennice. Wskazuje na to sceneria 
Koloseum i pieśń śpiewana w godzinie śmierci za wiarę, jak i sformułowanie „niebo im dało świętą aureolę". Nietrudno zgadnąć, że na tej wstędze jedną z ostatnich idących śladem Antygony jest Polska, która przez swoje męczeństwo dostąpi zbawienia.

Stanowi to świetne wprowadzenie do niezwykle istotnego przykładu takiego aktu komunikacji, który wielopoziomowo wykorzystał mit Antygony w wyraźnie „politycznym” celu. Mowa rzecz jasna o Wyspiańskim jako autorze Wyzwolenia, w którego II akcie Konrad w dialogu z Maską 18 wypowiada charakterystyczne i dość często potem w literaturze przywoływane zdanie: „Ma więc wyjść polska Antygona i polski Edyp i mają żegnać słońce i żegnać światło" (Wyspiański 1959: 124-125). W tym tajemniczym fragmencie, niezbyt jasnym, podobnie jak cały akt z Maskami, zastanawia takie ustawienie gestu polskiej Antygony, który ma polegać na pożegnaniu słońca z jednoczesnym przekleństwem jego światła. Podobnie jak ustawienie gestu Edypa, który ma sięgnąć po bluźnierstwo wobec Boga za zesłanie nań świadomości swojej sytuacji i - w efekcie - śmierci. Pomijając tymczasem rozważania na temat roli i funkcji Masek w Wyzwoleniu, wypada zauważyć konstatację Konrada, że takich Antygon i takich Edypów u nas pełno: „Nie jesteśmyż my tą siłą ducha onych przejęci?”. W kontekście tej konstatacji postulat „Ma więc wyjść polska Antygona ...” brzmi ironicznie, nie jak postulat w rzeczy samej, ale jako prześmiewcza, szydercza diagnoza przyzwyczajeń i skojarzeń związanych z „uderzaniem w wielki dzwon” (ibid.), o którym mowa chwilę wcześniej w tekście.

W tym kontekście warto spojrzeć także na fakt, że to za sprawą Wyspiańskiego rozpoczęły się sceniczne losy polskiej Antygony. To on bowiem przygotowywał prapremierę na scenie Teatru Miejskiego 25 kwietnia 1903 roku, zestawiając w jeden wieczór właśnie tragedię Sofoklesa z prapremierą swojego dramatu Protesilas i Laodamia. W obu tytułowe role kobiece zagrała sześćdziesięciotrzyletnia Helena Modrzejewska. Jak przekonująco udowodnił kilka lat temu Dariusz Kosiński (2004: 239-269), był to zabieg przemyślany i celowy, by oba teksty, rozdzielone antraktem, połączyć w jeden teatralny wieczór. Antygona, z którą mogło się wówczas utożsamić wiele matek, wdów, sióstr i córek obecnych na widowni, stanowiła rodzaj komentarza do postaci Laodamii, która - podobnie jak Antygona - „kocha się w śmierci” i przejmująco odkrywa, że jeśli chce się połączyć ze zmarłym kochankiem i mężem, to po prostu musi umrzeć. Kosiński dobitnie pokazał, że cały ten teatralny wieczór, obie prapremiery to ciąg dalszy rozprawy Wyspiańskiego z romantyzmem, w szczególności z mechanizmem Dziadów, który zdaniem autora Akropolis skutecznie blokuje możliwość jakiekolwiek działania, spychając wspólnotę nie ku wolności („wyzwoleniu”), a ku martwocie i niespełnieniu.

Innym twórcą, który za pomocą mitu Antygony próbował oddać zmieniającą się rzeczywistość Polski końca lat trzydziestych (zwłaszcza jesieni 1939 roku), był Juliusz Osterwa. Nosił się on z zamiarem wystawienia tej tragedii wpierw na wawelskim placu zamkowym, potem - wobec trudności organizacyjnych - w Teatrze im. Słowackiego w Krakowie, co się ostatecznie nie udało. Osterwa zamówił nowe tłumaczenie u Ludwika Hieronima Morstina, który wywiązał się z powierzonego mu zadania, nie przypuszczając jeszcze, że własny przekład również jemu wyznaczy rytm oswajania się z wojenną rzeczywistością. Jak bowiem Osterwa tuż po wybuchu wojny w swoim warszawskim mieszkaniu - począwszy od października 1939 roku - pisał autorską parafrazę sofoklejskiej Antygony (tylko w partiach chóru zostawiając poetycki przekład Morstina), by oswoić los zrzucający kolejny dopust na Polskę, tak i Morstin w swojej Antygonie uczynił z głównej bohaterki patronkę 
wojowniczek o niepodległość Polski w czasie II wojny światowej. I o ile parafraza Osterwy mimo starań nigdy nie ujrzała światła ramp scenicznych, o tyle w przypadku Morstina mamy do czynienia z bardzo przejmującą realizacją tego dramatu w czasie wojny w jego dworku w Pławowicach, „przed kolumnami starego pałacu” (Morstin 1945: 45). Wszystkie role grały dziewczyny i wszyscy uczestnicy tego wojennego misterium zgodnie podkreślają w powojennych relacjach, że nie było osoby na widowni, która by nie płakała - tak silnie gest i dylemat Antygony spajał się wówczas z sytuacją widzów. Po wojnie, kiedy Karol Frycz zdecydował o wprowadzeniu antycznej tragedii Sofoklesa na afisz krakowskiego teatru, Morstin - wzorem Morawskiego - dopisał specjalny prolog wygłoszony na scenie przed premierą Antygony. Aż roi się w nim od sformułowań odnoszących się do „nowego ładu” czy „budowania nowego świata”, zarazem pełno jest apelów o sprawiedliwy osąd obu stron, które walczyły za ojczyznę.

Patrząc na dzieje sceniczne Antygony w bardzo szczególnym okresie, jeśli chodzi o narodową czy wspólnotową komunikację w teatrze, jakim był okres PRL-u, należy pamiętać w szczególności o kilku dość istotnych okolicznościach. Po pierwsze Antygona była lekturą szkolną, co w przypadku polityki repertuarowej teatrów, zwłaszcza teatrów prowincjonalnych, stanowiło podstawowy powód sięgania po ten utwór. Po drugie na dziejach scenicznych dramatu Sofoklesa w okresie PRL-u zaważyła po części polska prapremiera dramatu Jeana Anouilha pt. Antigone, który został napisany jeszcze w czasie II wojny światowej, w roku 1943, a wystawiony był po raz pierwszy we Francji w lutym 1944 roku. Dramat ten, należący do jego pesymistycznych „czarnych sztuk”, doczekał się polskiej prapremiery w bardzo szczególnym momencie i przy bardzo ciekawej konfiguracji twórców. Tekst ten w przekładzie Zbigniewa Solarka wyreżyserował w Starym Teatrze Jerzy Kaliszewski, jego asystentem był wówczas Jerzy Grotowski, a scenografię projektował Tadeusz Kantor. Premiera odbyła się 12 stycznia 1957 roku. Do 1989 roku dokonano jeszcze piętnastu innych wystawień. Po trzecie wreszcie należy mieć na uwadze, że stosunkowo często sięgano także po Króla Edypa Sofoklesa (w okresie 1944-1989 dwadzieścia dwie realizacje w teatrach dramatycznych), co niejednokrotnie blokowało drogę na scenę Antygonie (i odwrotnie), pozostałe dramaty Sofoklesa nie cieszyły się już taką popularnością. Po czwarte nie można zapomnieć, że o sukcesie lub niepowodzeniu planowanego przekazu decydowały w znacznej mierze przekłady. Reżyserzy decydowali się zarówno na stary przekład Morawskiego (do dzisiaj grywany) napisany jedenastozgłoskowcem białym, jak i na trzynastozgłoskowiec Morstina czy przekład z języków zachodnich prozą Stanisława Hebanowskiego lub też na samodzielne, autorskie parafrazy (Helmut Kajzar, Józef Jasielski), z których korzystali później i inni reżyserzy. Często pojawiały się warianty kombinowane. Poza względami metrycznymi ważne są różnice $\mathrm{w}$ rozumieniu istoty tragizmu czy też modyfikowanie obrazu postaci na etapie przekładu - szczególnie widać to przez porównanie autoprezentacji Antygony w pierwszej rozmowie z siostrą oraz w tzw. mowie tronowej Kreona ( $w$ tym drugim zestawieniu uderza także „polonizacja” danego przekładu w zależności od momentu historycznego, w którym powstało tłumaczenie). Po piąte jednym z kluczowych problemów, na który należy zwrócić uwagę i z którym każdorazowo musieli się mierzyć realizatorzy, jest ukształtowanie przestrzeni i scenografia (a projektowali ją do Antygony wybitni artyści: Karol Frycz, Andrzej Pronaszko, Wiesław Lange, Józef Szajna, Jerzy Nowosielski, Krystyna Zachwatowicz, Jerzy Grzegorzewski, Jadwiga Pożakowska). Po szóste wreszcie problematyczne pozostaje przesuwanie akcentów w rozumieniu istoty tragicznego sporu obojga antagonistów, co skutkuje 
takim, a nie innym ustawieniem relacji między nimi (najczęściej, zwłaszcza w „szkolnych” realizacjach, rację ma Antygona, ale np. Adam Hanuszkiewicz w swoim przedstawieniu wzmocnił racje granego przez siebie Kreona).

Antygona była wykorzystywana także w polskim teatrze jako materiał do ukazania metateatralnego chwytu "teatru w teatrze”, przyjmując wówczas charakter próby, w ramach której współcześni ludzie „przymierzają się” do antycznego mitu. Taki charakter miały m.in. telewizyjne przedstawienie Jerzego Gruzy i spektakl Ryszarda Smożewskiego w krakowskim Teatrze Rozmaitości. Ten ostatni zresztą, wystawiony w 1969 roku, był wyraźnym protestem przeciwko rządom junty w Grecji. Piosenki do tego przedstawienia napisał Grek Mikis Theodorakis, a uwspółcześnienie przedstawienia polegało m.in. na dodaniu przez inscenizatora takich postaci, jak Tajniak, Policjant czy Ochrona Kreona. Także miejsce akcji nie pozostawiało wątpliwości, że rzecz dzieje się w jednym z teatrów ateńskich w czasie próby generalnej Antygony. Takie aktualizacje, oczywiście czytelne i zazwyczaj dobrze odbierane przez widownię, często spotykały się z grymasami krytyki.

Krytyczne przyjęcie spotkało np. spektakl Andrzeja Wajdy w krakowskim Starym Teatrze (premiera w 1984 roku), gdzie reżyser historię Antygony umieścił w realiach stanu wojennego. Kreon w ciemnych okularach jednoznacznie kojarzył się z gen. Wojciechem Jaruzelskim, chór w waciakach - ze współczesnymi robotnikami i strajkującymi stoczniowcami. Antygona zaś (pierwotnie miała ją grać Ewa Demarczyk, „czarny anioł” Piwnicy pod Baranami) stała się głosem zdławionej „Solidarności”. Spektakl uzyskał zgodę cenzury na premierę wyłącznie pod warunkiem, że nie będzie grany poza macierzystą sceną. Dopiero przełom 1989 roku otworzył szansę pokazu przedstawienia w Warszawie, które - po latach - nie wzbudziło już takich emocji warszawskiej publiczności.

$\mathrm{Z}$ podobną reakcją w zupełnie odmiennych warunkach komunikacyjnych spotkał się film Katyń nakręcony w 2007 roku, w którym reżyser również użył mitu Antygony do zobrazowania specyfiki zbrodni stalinowskiej i kłamstwa katyńskiego. Jednym z ważniejszych motywów w tym filmie jest bowiem wątek dwóch sióstr, które straciły w Katyniu brata, porucznika rezerwy. Pierwsza z nich, Agnieszka, uczestniczka powstania warszawskiego, pragnie uczcić pamięć brata tablicą pamiątkową z napisem „zmarł tragicznie w Katyniu w kwietniu 1940 roku" (Wajda 2007). Druga, Irena, pracuje jako dyrektorka liceum i, choć nie jest członkiem partii, z racji piastowanego stanowiska nie może poprzeć działań siostry, sama przyjmuje do szkoły młodego partyzanta z Armii Krajowej mimo jego uporu - chłopak nie chce przeformułować życiorysu złożonego wraz z podaniem. By zdobyć środki na wykonanie tablicy, Agnieszka (tak miała też na imię inna nonkonformistyczna bohaterka Wajdy: Agnieszka z Człowieka z marmuru i Człowieka ż̇elaza) sprzedaje swoje włosy na perukę w teatrze, gdzie akurat wystawiana jest Antygona Sofoklesa. W czasie obcinania włosów Agnieszce przez teatralnego fryzjera aktorka przygotowująca się do roli Antygony recytuje fragment z dramatu Sofoklesa. Prawdziwą Antygoną postawioną przed „trybunał szaleńca” jest jednak właśnie Agnieszka, która pragnie uczcić pamięć zmarłego brata. Zaprzyjaźniony ksiądz kanonik odmawia umieszczenia epitafium w kościele, Agnieszka decyduje się więc na tymczasowe umieszczenie jej na rodzinnym grobowcu. Kilka chwil po jej zamontowaniu SB zabiera Agnieszkę na przesłuchanie, a sama tablica szybko ulega zniszczeniu. W siedzibie służb Agnieszka odmawia podpisania oświadczenia, jakoby sprawcą zbrodni katyńskiej byli Niemcy. Ostatnią sceną, w jakiej widzimy Agnieszkę, jest moment zejścia do esbeckich piwnic, kiedy patrzy w górę na słabe, migoczące światło lampy. 
Mit Antygony znalazł także zupełnie nieoczekiwaną kontynuację w ceremoniach i dyskusjach związanych z katastrofą lotniczą pod Smoleńskiem ${ }^{7}$. Warto w tym momencie przywołać spostrzeżenia Kosińskiego, który ukazuje nam mit Antygony w zupełnie nowym użyciu:

Interesujące wydaje się także to, że gwałtowne protesty przeciwko pochówkowi na Wawelu stosunkowo szybko ucichły (czy też raczej zeszły do swoistego podziemia, gdzie tkwią do dziś, czekając, być może, na erupcję). Odegrało w tym rolę, jak sądzę, poczucie, że dokonuje się akt nie osobisty i nie polityczny (choć przecież i takich motywacji nie można wykluczyć), ale wspólnotowy. Odegrał też rolę mit Antygony i swoiste przemieszanie tradycyjnego układu tamtego dramatu, tak mocno wpisanego symbolicznie w niedawną historię. Oto „Antygona”, pozbawiona władzy i będąca w mniejszości, domaga się niepochowania ciała, podczas gdy „Kreon” chce pogrzebu, i to uroczystego. Klasyczny (i szkolnie uproszczony) konflikt władzy świeckiej, religijnej i mityczno-rytualnej (trzeba wszak grzebać zmarlych) przekształcił się w jej sojusz, któremu właściwie nie dało się skutecznie przeciwstawić (Kosiński 2010: 7-8).

Doskonale wyczuli to twórcy jednego z najlepszych kabaretów ostatniego dwudziestolecia, zielonogórskiej formacji Potem, którzy bardzo przenikliwie obśmiali mit Antygony, od dawna i wciąż tak żywo rezonujący z rzeczywistością i stanem polskiej wspólnoty państwowej czy narodowej (Potem 2010). W finale skeczu z towarzyszeniem chóralnie śpiewanej pieśni Budujemy nowy dom wyprowadzają Antygonę ze sceny (pojawia się jeszcze Zeus z okrzykiem „Ale mnie wkurzyłeś!”, na co Kreon reaguje okrzykiem „O Jezu!”, a Zeus złowrogo grozi mu „Ja ci dam Jezu!”). Mit Antygony trafil pod kabaretowe strzechy, to znak, że czas otrząsnąć się z grobowego i politycznego wymiaru tej dramatyzacji. Równocześnie potwierdzenie, jak głęboko umiejscowił się w naszym życiu zbiorowym.

W artykule chcieliśmy syntetycznie wskazać dominujące, naszym zdaniem, tendencje oraz możliwości badawcze we współczesnych polskich studiach nad recepcją antyku grecko-rzymskiego. Znaczna ich część wciąż jest skoncentrowana na literaturze, powoli przebijają się pozycje poświęcone recepcji antyku w kulturze popularnej oraz w teatrze. Najsilniejszym jednak nurtem polskich badań recepcyjnych są opracowania poświęcone mitom starożytnym i ich funkcjonowaniu w kulturze. Nie mamy wątpliwości, że przeglądowe, niejednokrotnie enumeracyjne, prace powstałe jeszcze kilkadziesiąt lat temu (z których część wymieniliśmy) umożliwiły pogłębienie analiz i kontekstów (społecznych, filozoficznych, politycznych i in.) zawartych w pracach typu case studies, jak staraliśmy się to pokazać na przykładzie Antygony, bohaterki tragedii Sofoklesa. Przykład ten dowodzi jednak także tego, że badacz recepcji jest dzisiaj skazany na dwa rozwiązania: na pozyskiwanie coraz szerszych kompetencji, jeśli swoją pracę chce wykonać sam, bądź też wejście w skład zespołu badaczy o różnych kompetencjach i zainteresowaniach. Wymienione bowiem w naszym artykule kierunki badawcze wskazują, że badania nad starożytnością klasyczną oraz jej wpływami na kulturę nowożytną i współczesną z konieczności stają się coraz częściej badaniami interdyscyplinarnymi, łączącymi nie tylko różne dziedziny humanistyki i nauk społecznych, jak również wykorzystującymi inne, poza tradycyjnymi papierowymi, nośniki i metody

\footnotetext{
7 Por. inscenizacja Antygony w reżyserii Marcina Libera z Teatru Nowego w Łodzi (2013).
} 
prezentacji wyników badań, w tym szczególnie techniki cyfrowe ${ }^{8}$. Przedstawienie wpływów dziedzictwa kultury grecko-rzymskiego antyku (nawet na przykładzie tylko jednej kultury) od średniowiecza do czasów współczesnych przekracza objętość artykułu, zwłaszcza że wpływy te można śledzić na wielu płaszczyznach kulturowych, poczynając od języków europejskich, które narodziły się z języka łacińskiego (języki romańskie), spokrewnione są z językiem łacińskim (języki germańskie) bądź wykazują silne wpływy języka łacińskiego (np. języki słowiańskie zachodnie): w literaturze, muzyce, plastyce, teatrze, architekturze, krytyce, edukacji, lingwistyce, filozofii, prawie, retoryce, medycynie, nauce itd. Recepcja antyku odbywa się przez bezpośrednie nawiązywanie (imitatio) do wątków, motywów, tematów czy schematów wypracowanych w starożytności, ale także poprzez współzawodniczenie z nimi (aemulatio), poprzez wykorzystywanie ich, inspirowanie się nimi, przekształcanie ich. $Z$ tego punktu widzenia klasyczną, a zarazem monumentalną pozycją, liczącą 800 stron, omawiającą wpływy antyku na literaturę europejską jest książka Gilberta Higheta The Classical Tradition. Greek and Roman Influences on Western Literature. Z konieczności jest pozycją przeglądową i siłą rzeczy nieuwzględniającą najnowszych badań. A te, szczególnie dotyczące recepcji kultury starożytnej, mają się całkiem dobrze, zwłaszcza jeśli przypomnimy, że nauczanie starożytności zostało niemal całkowicie usunięte ze współczesnych programów nauczania - wielu badaczy zajmuje się recepcją antyku w różnych kulturach świata, powstają publikacje, serie wydawnicze czy zespoły naukowe. Jak wyżej staraliśmy się pokazać, dzieje się tak również w kulturze polskiej. Wobec spadającej znajomości języków klasycznych niektórzy właśnie w badaniach recepcyjnych upatrują szansy na przechowanie i utrwalenie tradycji antycznej w czasach, w których, jak pisaliśmy na wstępie, straciła ona swoją elementarną rolę w inteligenckim kodzie wspólnotowym. Może jest to właściwa droga, by antyk ponownie stał się uniwersalnym, zrozumiałym językiem służącym jako pomost między przeszłością a teraźniejszością.

\section{Bibliografia}

Bibik, Barbara 2006. „Mowa pożegnalna Antygony. Próba porównania wybranych tłumaczeń czwartego epejsodion Antygony Sofoklesa na język polski”. Nowy Filomata 2: 89-100.

- 2009-2012. „Antygona - męczennica?”. Meander 64-67: 5-29.

- 2012. „O Profesorze Stefanie Srebrnym - tłumaczu i inscenizatorze słów kilka”. Rocznik Toruński 39: 207-221.

— 2015. „Profesor Stefan Srebrny jako tłumacz (na przykładzie Orestei Ajschylosa)”. W: Grażyna Golik-Szarawarska (red.). Wartości formalne antycznego dramatu i teatru greckiego. Katowice: Wydawnictwo Uniwersytetu Śląskiego.

- 2016a. „Didaskalia w Orestei Ajschylosa jako projekt inscenizacji tłumacza (na przykładzie Ofiarnic)". Przektadaniec 31: 75-89.

- 2016b. „Didaskalia w Orestei Ajschylosa jako projekt inscenizacji tłumacza (na przykładzie Agamemnona)". Symbolae Philologorum Posnaniensium Graecae et Latinae 26: 53-75.

\footnotetext{
8 Warto tu wymienić, mimo ograniczenia tematycznego tego artykułu, zrealizowany projekt "Scrinium Augustini. The World of Augustine's Letters" (http://www.scrinium.umk.pl), poświęcony listom św. Augustyna, realizowany na Uniwersytecie Mikołaja Kopernika, oraz realizowany na Uniwersytecie Warszawskim projekt „Prezbiterzy na późnoantycznym Zachodzie”, którego wyniki dostępne będą również w formie cyfrowej.
} 
— 2016c. „Przekłady starożytnych utworów dramatycznych - w zgodzie czy wbrew normom? Kilka refleksji o tradycji przekładoznawczej”. Między Oryginatem a Przekładem 22: 119-136.

- 2016d. „Zygmunt Węclewski Under the Influence of the XIXth Century's Theatre and Literature”. Eos 104: 363-376.

- 2016e. Translatoris vestigia. Projekcje inscenizacyjne wybranych polskich thumaczy Orestei Ajschylosa. Toruń: Wydawnictwo Uniwersytetu Mikołaja Kopernika.

Bieńkowski, Tadeusz 1976. Antyk w literaturze i kulturze staropolskiej (1450-1750): główne problemy i kierunki recepcji. Wrocław: Zakład Narodowy im. Ossolińskich, Wydawnictwo Polskiej Akademii Nauk.

Bocheński, Jacek 2010. Antyk po antyku. Warszawa: Świat Książki.

Borowska, Małgorzata, Maria Kalinowska, Jerzy Speina, Katarzyna Tomaszuk (red.) 2014. Sparta w kulturze polskiej. Cz. 1: Model recepcji, spojrzenie europejskie, konteksty greckie. Warszawa: Wydawnictwo Naukowe Sub Lupa.

Borowska, Małgorzata, Damian Kaja, Maria Kalinowska, Jerzy Speina (red.) 2015. Sparta w kulturze polskiej. Cz. 2: Przekroje, syntezy, konteksty. Warszawa: Wydawnictwo Naukowe Sub Lupa.

Brożek, Mieczysław 1996. „O tłumaczu i tłumaczeniu myśli wybrane”. Meander 7-8: 397-399.

Brzuska, Barbara 1992. Filologia klasyczna w Szkole Głównej Warszawskiej. Wrocław: Zakład Narodowy im. Ossolińskich.

Budelman, Felix, Haubold, Johannes 2008. „Reception and Tradition”. W: Hardwick, Lorna, Christopher Stray (eds.) 2008. A Companion to Classical Receptions. Oxford: Blackwell Publishing.

Budzowska, Małgorzata 2018. Sceniczne metamorfozy mitu. Teatr polski XXI wieku w perspektywie kulturowej. Łódź: Wydawnictwo UŁ.

Budzowska, Małgorzata, Jadwiga Czerwińska (red.) 2014. Ancient Myths in the Making of Culture. Frankfurt am Main et al.: Peter Lang.

Budzowska, Małgorzata, Burc I. Dinçel, Jadwiga Czerwińska, Katarzyna Chiżyńska (red.) 2017. The Metamorphoses of Ancient Myths. Frankfurt am Main: Peter Lang.

Chojecki, Dariusz 2000. Antyk w zbiorach muzeów Górnego Śląska. Racibórz: Muzeum w Raciborzu.

Domański, Jerzy 2009. Philologica, Litteraria, Humaniora. Studia i szkice z dziejów recepcji dziedzictwa antycznego. Warszawa: Wydział Polonistyki UW.

Dominas, Konrad 2017. Internet jako nowa przestrzeń recepcji literatury antycznej. Poznań: Pracownia Humanistycznych Studiów Interdyscyplinarnych, Wydział Filologii Polskiej i Klasycznej. Uniwersytet im. Adama Mickiewicza.

Guzowska, Marta 2012. Ofiara Polikseny. Warszawa: Wydawnictwo Foksal.

- 2013. Gtowa Niobe. Warszawa: Wydawnictwo Foksal.

Hardwick, Lorna 2003. Reception Studies. Greece and Rome New Surveys in the Classics. Oxford: Oxford University Press.

Hardwick, Lorna, Christopher Stray (eds.) 2008. A Companion to Classical Receptions. Oxford: Blackwell Publishing.

Hardwick, Lorna, Stephen Harrison (eds.) 2013. Classics in the Modern World. A „Democratic Turn”?. Oxford: Oxford University Press.

Herbert, Zbigniew 2000. Labirynt nad morzem. Warszawa: Fundacja Zeszytów Literackich.

Hermann, Marek 2014. O tacinie tylko dobrze. De lingua Latina nil nisi bene. Kraków: Towarzystwo Autorów i Wydawców Prac Naukowych „Universitas”.

Heydel, Magda 2009. „Zwrot kulturowy w badaniach nad przekładem”. Teksty Drugie 6: 21-33.

Highet, Gilbert 1949. The Classical Tradition. Greek and Roman Influences on Western Literature. Oxford: Oxford University Press.

Jastrzębowska, Elżbieta 1993. Antyk w Zamku Królewskim w Warszawie: stownik antycznych postaci historycznych i mitologicznych, symboli, alegorii, ornamentów $i$ detali architektonicznych. Warszawa: Zamek Królewski w Warszawie. 
Kallendorf, Craig (ed.) 2007. A Companion to Classical Tradition. Oxford: Blackwell Publishing.

Kasdepke, Grzegorz 2009. Mity dla dzieci. Łódź: Wydawnictwo Literatura.

- 2011. Zeus \&́ spótka. Mity dla dzieci. Łódź: Wydawnictwo Literatura.

Katullus 2013. Poezje wszystkie. Tłum. Grzegorz Franczak, Aleksandra Klęczar. Kraków: Homini.

Kosiński, Dariusz 2004. Sceny z życia dramatu. Kraków: Księgarnia Akademicka.

- 2010. „Polska w żałobie. Między obrzędem a ceremonią”. Teatr 7-8: 27-34.

Krajewski, Marek 2009. Gtowa Minotaura. Kraków: Wydawnictwo Znak.

- 2010. Erynie. Kraków: Wydawnictwo Znak.

- 2011. Liczby Charona. Kraków: Wydawnictwo Znak.

- 2012. Rzeki Hadesu. Kraków: Wydawnictwo Znak.

Kubiak, Zygmunt 1969. Wędrówki po stuleciach. Kraków: Znak.

- 1998. Brewiarz Europejczyka. Warszawa: Biblioteka „Więzi”.

- 2000. Uśmiech Kore. Warszawa: Biblioteka „Więzi”.

- 2001a. Nowy brewiarz Europejczyka. Warszawa: Biblioteka „Więzi”.

- 2001b. Pótmrok ludzkiego świata. Kraków: Znak.

Lorentz, Stanisław (red.) 1989. Antyk w kulturze Oświecenia. Warszawa: Wydawnictwa Uniwersytetu Warszawskiego.

Lowe, Dunstan, Kim Shahabudin (eds.) 2009. Classics for All. Reworking Antiquity in Mass Culture. Newcastle: Cambridge Scholars Publishing.

Łanowski, Jerzy 1997. „Przekłady dramatu antycznego. Z doświadczeń tłumacza”. W: Jerzy Axer, Zbigniew Osiński (red.). Siew Dionizosa. Inspiracje Grecji antycznej w teatrze i dramacie XX wieku w Europie Środkowej i Wschodniej. Warszawa: OBTA i DiG.

Makowiecki, Andrzej Z. (red.) 2000. Literatura i czasopiśmiennictwo polskie 1864-1918 wobec tradycji antycznej. Warszawa: OBTA UW.

Marciniak, Katarzyna 2010. Mitologia grecka i rzymska. Warszawa-Bielsko-Biała: Wydawnictwo Szkolne PWN.

- 2013. „Tradycja antyczna w XXI wieku - cui bono?”. W: Katarzyna Marciniak (red.). Antyk i my w Ośrodku Badań nad Tradycją Antyczna. Warszawa: Wydział „Artes Liberales” UW.

- 2016a. Moja pierwsza mitologia. Księga I. Warszawa: Nasza Księgarnia.

- 2016b. Moja pierwsza mitologia. Księga II. Warszawa: Nasza Księgarnia.

Marciniak, Katarzyna, Elżbieta Olechowska, Joanna Kłos, Michał Kucharski (eds.) 2013. Polish Literature for Children \& Young Adults Inspired by Classical Antiquity. Warszawa: OBTA.

Marciniak, Katarzyna (ed.) 2016. Our Mythical Childhood... The Classics and Literature for Children and Young Adults. Leiden-Boston: Brill.

Mikołajczak, Aleksander 1994. Antyk w poezji Macieja Kazimierza Sarbiewskiego. Poznań: Polinfo.

Mikołajczak, Aleksander, Konrad Dominas, Rafał Dymczyk (red.) 2015. Antykw zwierciadle literatury $i$ kultury popularnej. Poznań: Pracownia Humanistycznych Studiów Interdyscyplinarnych.

Morstin, Ludwik Hieronim 1945. „Teatr antyczny a my”. Teatr 1: b.s.

Nerczuk, Zbigniew 2016. „O specyfice pracy thumacza antycznej literatury filozoficznej”. Studia Antyczne i Mediewistyczne 14: 13-19.

Osterwa, Juliusz 2007. Antygona, Hamlet, Tobiasz dla Teatru Społecznego. Wrocław: Wydawnictwo Uniwersytetu Wroclawskiego.

Parandowski, Jan 1934. Dysk olimpijski. Warszawa: Gebethner i Wolf.

Pianko, Gabriela 1965. Antyk we wspótczesnym teatrze polskim: $w$ dwudziestolecie powstania Polskiej Rzeczypospolitej Ludowej. Warszawa: Państwowe Wydawnictwo Naukowe.

Podbielski, Henryk (red.) 2005. Literatura Grecji starożytnej. Lublin: Towarzystwo Naukowe Katolickiego Uniwersytetu Lubelskiego.

Pollak, Seweryn (red.) 1975. Przekład artystyczny. O sztuce thumaczenia, księga druga. Wrocław: Zakład Narodowy im. Ossolińskich.

Potem. „Antygona”. https://www.youtube.com/watch?v=G3blUY1-Eb8 [03.07.2018]. 
Rusinek, Michał (red.) 1955. O sztuce ttumaczenia. Wrocław: Zakład Narodowy im. Ossolińskich.

Rusnak, Radosław 2009. Seneca noster, część I - studium o dawnych przekładach Seneki Młodszego. Warszawa: Wydział Polonistyki UW.

Sandauer, Artur 1977. „Źle o poprzednikach”. W: Edward Balcerzan (red.). Pisarze polscy o sztuce przektadu. Poznań: Wydawnictwo Poznańskie.

Sarnowska-Temeriusz, Elżbieta, Alina Brodzka (red.) 1992. Topika antyczna w literaturze polskiej XX wieku. Wrocław: Zakład Narodowy im. Ossolińskich.

Sinko, Tadeusz 1909. Hellenizm Juliusza Stowackiego. Kraków: Akademia Umiejętności.

- 1912a. „Jedno ze źródeł Irydiona”. Pamiętnik Literacki 11: 145-152.

- 1912b. „Eacińskie prace Krasińskiego”. Pamiętnik Literacki 11: 138-142.

- 1912c. „Rzym pogański w Irydionie”. Pamiętnik Literacki 11: 10-56.

- 1916. Antyk Wyspiańskiego. Kraków: Akademia Umiejętności.

- 1918. Genealogia kilku typów i figur A. Fredry. Kraków: Akademia Umiejętności.

- 1923a. Echa klasyczne w literaturze polskiej. Dwanaście studiów i szkiców. Kraków: Krakowska Spółka Wydawnicza.

- 1923b. O tradycjach klasycznych Adama Mickiewicza: rozpraw pięcioro. Kraków: Krakowska Spółka Wydawnicza.

- 1924. „Powinowactwo klasyczności i romantyczności”. Przegląd Wspótczesny 9:397-410.

- 1931-1951. Literatura grecka. Kraków: Polska Akademia Umiejętności.

- 1933a. „Klasyczny laur Norwida”. Przeglad Powszechny 198-199: 288-305.

- 1933b. Hellada i Roma w Polsce: przegląd utworów na tematy klasyczne w literaturze polskiej ostatniego stulecia. Lwów: Państwowe Wydawnictwo Książek Szkolnych.

- 1939. Od filantropii do humanizmu i humanitaryzmu. Lwów: Państwowe Wydawnictwo Książek Szkolnych.

- 1947. „Posąg Europy i jego losy”. Meander 8: 431-444.

- 1954. Literatura grecka. Wrocław: Zakład Narodowy im. Ossolińskich.

- 1957. Mickiewicz i antyk. Wrocław-Kraków: Zakład Narodowy im. Ossolińskich.

- 1988. Antyk w literaturze polskiej. Prace komparatystyczne. Warszawa: Państwowe Wydawnictwo Naukowe.

Skwara, Ewa 1996. „Plaut w polskich przekładach”. Eos 84: 335-343.

- 2004. „Skąd się biorą didaskalia w przekładach dramatów antycznych? Exemplum: Asinaria Plauta w tłumaczeniu Ewy Skwary". Symbolae Philologorum Posnaniensium Graecae et Latinae 16: 67-76.

- 2008. „Spektakl zaklęty w tekście. Wizja antycznego przedstawienia Captivi Plauta”. W: Justyna Olko (red.). Obrzęd, teatr, ceremoniat $w$ dawnych kulturach. Warszawa: Wydawnictwo DiG, Ośrodek Badań Interdyscyplinarnych „Artes Liberales” UW.

— 2009. „Eros z patyną. Kilka przykładów z antycznej komedii w sprawie historii przekładu erotyki”. Przekładaniec 21: 55-62.

- 2012. „Kłopotliwi mistrzowie, czyli o rymotwórcach tlumaczących literaturę antyczną”. Przektadaniec 26: 150-164.

Sofokles 1916. Tragedye. Tłum. Kazimierz Morawski. Kraków: Akademia Umiejętności.

- 1956. Król Edyp. Edyp w Kolonie. Antygona. Tłum. Ludwik Hieronim Morstin. Warszawa: Państwowy Instytut Wydawniczy.

Srebrny, Stefan 1984. Teatr grecki i polski. Warszawa: Państwowe Wydawnictwo Naukowe.

Stabryła, Stanisław 1980. Antyk we wspótczesnej literaturze polskiej. Wrocław: Zakład Narodowy im. Ossolińskich.

- 1983. Hellada i Roma w Polsce Ludowej. Recepcja antyku w literaturze polskiej w latach 1945-1975. Kraków: Wydawnictwo Literackie.

- 1995. Klątwa Pelopidów. Kraków: Oficyna Literacka. 
- 1996. Hellada i Roma: recepcja antyku w literaturze polskiej w latach 1976-1990. Kraków:

Księgarnia Akademicka.

- 2016. Zarys kultury starożytnej Grecji i Rzymu. Warszawa: Oficyna Wydawnicza Aspra-JR, Bellona.

Stabryła, Stanisław (red.) 1992. Mit, człowiek, literatura. Warszawa: Wydawnictwo Naukowe PWN.

Stańczak, Wojciech 1986. Antyk we wspótczesnej poezji polskiej: 1956-1980. Wrocław: Zakład Narodowy im. Ossolińskich.

Starnawski, Jerzy 2010. Antyk wciąż żywy. Łódź: Wydawnictwo „Primum Verbum”.

Starnawski, Jerzy, Maria Wichowa, Andrzej Obrębski 1992. Antyk w Polsce, cz. 1. Łódź: Wydawnictwo Uniwersytetu Łódzkiego.

Starnawski, Jerzy, Jan Okoń 1998. Antyk w Polsce, cz. 2. Studia. Łódź: Wydawnictwo Uniwersytetu Łódzkiego.

Steiner, George 1996. Antigones. How the Antigone Legend has Endured in Western Literature, Art, and Thought. New Haven-London: Yale University Press.

Szamałek, Jakub 2011. Kiedy Atena odwraca wzrok. Warszawa: Wydawnictwo Muza.

Tibullus 2015. Elegie miłosne. Tłum. Aleksandra Arndt. Kraków: Homini.

Wajda, Andrzej (reż.) 2007. Katyń. [Film]. Warszawa; https://vod.pl/filmy/katyn-online/fcw5wgb [4.07.2018].

Wichowa, Maria 2008. Staropolskie przekłady Metamorfoz Owidiusza. Łódź: Wydawnictwo Uniwersytetu Łódzkiego.

Wikarjak, Jan 1977. „Polskie przekłady Eneidy”. Symbolae Philologorum Posnaniensium 3: 91-173.

Winkler, Martin M. (ed.) 1991. Classics and Cinema. Lewisburg: Bucknell University Press.

Wyspiański, Stanisław 1959. Dzieła zebrane. T. 5. Kraków: Wydawnictwo Literackie.

Zabierowski, Stefan 1978. „Polskie Antygony”. Rocznik Komisji Historycznoliterackiej 15: 163-181.

Zieliński, Tadeusz 1970. Po co Homer? Świat antyczny i my. Kraków: Wydawnictwo Literackie.

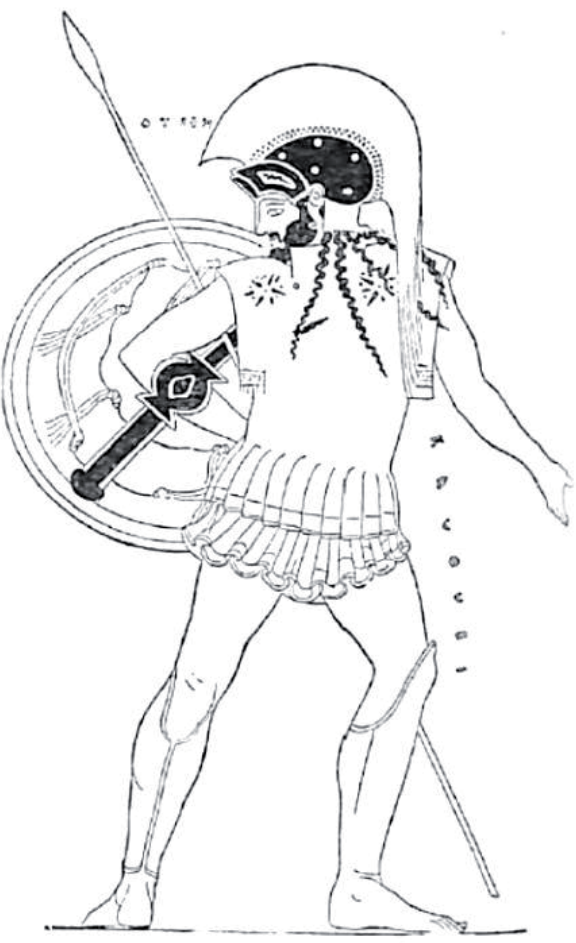

Hoplita z okrągłą tarczą

(źródło: Harder, Christian 1910. Schulwörterbuch zu Homers Ilias und Odyssee.

Zweite, verbesserte Auflage. Wien-Leipzig: F. Tempsky, G. Freytag, s. 46) 